\title{
Evaluating the association between single nucleotide polymorphisms in the stonin 2 (STON2) gene and keratoconus in a Han Chinese population
}

\author{
Jing Zhang ${ }^{1,2,3}$, Yue $\mathrm{Li}^{1,2,3}$, Yiqin Dai ${ }^{1,2,3}$, Jianjiang $\mathrm{Xu}^{1,2,3}$ \\ ${ }^{1}$ Eye Institute and Department of Ophthalmology, Eye \& ENT Hospital, Fudan University, Shanghai, China; ${ }^{2}$ NHC Key Laboratory of Myopia, \\ Fudan University, Shanghai, China; ${ }^{3}$ Shanghai Key Laboratory of Visual Impairment and Restoration, Shanghai, China \\ Contributions: (I) Conception and design: J Xu, J Zhang; (II) Administrative support: J Xu; (III) Provision of study materials or patients: J Xu; (IV) \\ Collection and assembly of data: J Zhang, Y Li, Y Dai; (V) Data analysis and interpretation: J Zhang; (VI) Manuscript writing: All authors; (VII) Final \\ approval of manuscript: All authors. \\ Correspondence to: Prof. Jianjiang Xu, MD, PhD. Department of Ophthalmology and Visual Science, Eye \& ENT Hospital, Shanghai Medical \\ College, Fudan University, Shanghai, China. Email: jianjiangxu@126.com.
}

Background: A recent genome-wide association study (GWAS) identified a significant association between the single nucleotide polymorphism (SNP) rs2371597 in the stonin 2 gene (STON2) and keratoconus (KCTN) susceptibility. The current study further explored the association between STON2 and KCTN susceptibility in an independent Han Chinese population.

Methods: Three SNPs (rs2371597, rs8004137, and rs8008602) located in the STON2 gene were examined in 164 Han Chinese patients with KCTN and 239 age- and gender-matched healthy subjects. The TaqMan SNP genotyping assays were performed, and the LDlink, RegulomeDB, and PLINK package were applied for data analyses. The gene expression levels of STON2 were investigated in various murine organ tissues using quantitative real-time polymerase chain reaction (qRT-PCR).

Results: The SNP rs2371597 was significantly associated with KCTN risk in this Han Chinese population. The frequency of the $\mathrm{C}$ allele in KCTN patients was significantly higher than that in healthy subjects [34.8\% vs. 26.6\%; odds ratio $(\mathrm{OR})=1.47$; $95 \%$ confidence interval (CI): 1.08 to 2.02; $\mathrm{P}=0.01409$ ]. The genotype distribution of the SNP rs2371597 was also significantly different between KCTN patients and controls. The other two genotyped SNPs allele and genotypic frequencies were not remarkably different between the KCTN group and the control group. However, the haplotype CAT formed by the three SNPs was substantially associated with the risk of $\operatorname{KCTN}(\mathrm{P}=0.04101)$. Also, gene expression pattern analysis showed a relatively higher expression of STON2 in the cornea in comparison to other tissues.

Conclusions: The current study demonstrated that SNPs in the STON2 gene were associated with an increased risk of developing KCTN in this Han Chinese population, suggesting that the STON2 gene may play an important role in the etiology of KCTN.

Keywords: Stonin 2 gene (STON2); keratoconus (KCTN); single nucleotide polymorphism (SNP); association study; Han Chinese population

Submitted Sep 27, 2020. Accepted for publication Jan 12, 2021.

doi: $10.21037 / \mathrm{atm}-20-6654$

View this article at: http://dx.doi.org/10.21037/atm-20-6654

(C) Annals of Translational Medicine. All rights reserved. 


\section{Introduction}

Keratoconus (KCTN) is a major indication for cornea transplantation in developed countries (1). It is characterized by progressive corneal thinning and conical protrusion, leading to severe visual disturbances (2). KCTN has an average prevalence of 1:2,000 globally but varies across different ethnicities. Asians are reported to have a remarkably higher incidence of KCTN than Caucasians, suggesting that ethnic differences might have considerable impacts on this disease (3). The clinical management of KCTN varies depending on the clinical stages. In the early stages, collagen UV cross-linking or contact lenses can stabilize the cornea biomechanics, thereby controlling KCTN progression (4). Therefore, early diagnosis of KCTN based on a clear understanding of its etiology may help guide clinical interventions.

The etiology of KCTN is multifactorial, combining both genetic and non-genetic factors. Environmental factors including UV exposure (5), contact lens wear (6), atopy (7), and constant eye rubbing (8) can all act as triggers of the condition in genetically predisposed individuals. However, more importantly, a strong genetic susceptibility underlying KCTN pathogenesis has been clearly demonstrated in familial aggregation studies $(9,10)$, twins studies (11), linkage analyses, and genome-wide association studies (GWASs) $(4,12)$. So far, over 150 single polynucleotide polymorphisms (SNPs) in more than 60 loci have been identified to be linked with KCTN susceptibility (13-20). Some SNPs were discovered in GWASs examining central corneal thickness (CCT), which is a critical quantitative trait locus (QTL) associated with increased KCTN risk. These identified loci include MDPZ-NF1B, FOXO1, FND 3B, COL4A3, COL4A4, and COL5A1 (21-23). While many of these reported loci have been detected in several other ethnicities, inconsistent results exist across different cohorts, rendering their contribution to KCTN risk inconclusive (18,24-27).

Recent GWASs identified the stonin 2 gene (STON2) as a susceptibility gene for CCT $(21,23)$. STON2 encodes a membrane protein that is involved in regulating endocytotic complexes. It is one of the clathrin-associated adaptor molecules which ensures that specific proteins are internalized (28). Hosoda et al. (23) discovered that the STON2 allele rs2371597, which was associated with increased CCT, was also associated with an increased risk of KCTN in the Japanese population. However, due to the underlying genetic heterogeneity of KCTN susceptibility, it remains unknown whether this SNP also confers the risk of KCTN susceptibility in other cohorts. It is also possible that other additional SNPs located in the same locus might contribute to KCTN susceptibility. Therefore, an extensive investigation on this locus is warranted. Herein, a replication study on the reported SNP rs2371597, together with two potential regulatory SNPs within the same locus, was carried out to explore the contribution of the STON2 locus to KCTN susceptibility in an independent Han Chinese population.

We present the following article in accordance with the MDAR reporting checklist (available at http://dx.doi. org/10.21037/atm-20-6654).

\section{Methods}

\section{Subjects}

A total of 164 Han Chinese patients with KCTN were randomly selected from the Department of Ophthalmology at the Eye and ENT Hospital of Fudan University between October 2015 and November 2018. All patients were selfreported as Han Chinese ethnicity. Patients were diagnosed with KCTN if they presented with at least one KCTN symptom, such as corneal stromal thinning, Fleischer's ring, Vogt's striae, or Munson's sign, and videokeratography showed refractive errors or signs. Patients with KCTN and syndromic disease (such as Down's syndrome and Leber optic atrophy) were excluded. A total of 239 healthy individuals with no signs of ocular disorder were included as the control group.

The study was conducted following the Declaration of Helsinki (as revised in 2013) and has been approved by the Ethics Committee of the Eye and ENT Hospital of Fudan University (2015044-1). Informed consent was obtained from all participants.

\section{Genomic DNA extraction}

Genomic DNA was extracted from the peripheral blood monocytes using the QIAGEN FlexiGene DNA kit (Qiagen, Hamburg, Germany) following the manufacturer's protocol. DNA concentration was measured with a NanoDrop spectrophotometer (NanoDrop Technologies, DE, USA).

\section{Genotyping of SNPs}

Three SNPs (rs2371597, rs8004137, and rs8008602) located in the STON2 gene were selected for investigation, utilizing 
Table 1 Basic characteristics of patients with KCTN and healthy controls

\begin{tabular}{lcc}
\hline Features & KCTN $(\mathrm{n}=164)$ & Controls $(\mathrm{n}=239)$ \\
\hline Gender (female/male) & $40 / 124$ & $89 / 150$ \\
Average age (years) & $23.64 \pm 6.17$ & $30.02 \pm 5.36$ \\
Age range (years) & $13-48$ & $15-41$ \\
Disease onset age (years) & $21.04 \pm 4.72$ & NA \\
Visual activity* & OS: $0.53 \pm 0.35 ;$ OD: $0.32 \pm 0.27$ & NA \\
\hline
\end{tabular}

*, average age and patients' visual activity are presented as mean \pm SD. KCTN, keratoconus; OS, oculus sinister; OD, oculus dexter; SD, standard deviation.

the TaqMan SNP Genotyping Assays (C__2791741_10 for rs2371597, C__29283383_10 for rs8004137, and C__29283385_10 for rs8008602). The genotyping assay was performed using real-time polymerase chain reaction (PCR; Applied Biosystems VII, USA) with the standard genotyping protocol. Each reaction contained $2 \mu \mathrm{L}$ DNA template, $5 \mu \mathrm{L}$ of MasterMix buffer $(2 \times$ concentration; ThermoFisher), $2.5 \mu \mathrm{L}$ double distilled water $\left(\mathrm{ddH}_{2} \mathrm{O}\right)$, and $0.25 \mu \mathrm{L}$ probe $(40 \times$ concentration). Genotypes were automatically determined using the ratio of VIC and FAM fluorescent signals from the TaqMan assay.

\section{Data analysis}

Data analysis was conducted with the PLINK package (29). SNP frequency in case and control group was tested for departure from HWE with an exact test. A $\chi^{2}$-test was used to calculate the difference in SNP allele frequency between cases and controls. The logistic regression model, adjusted by gender and age, was used to calculate the odds ratios (ORs) and the $95 \%$ confidence intervals (CIs). $\mathrm{P}$ values less than 0.05 were considered statistically significant. The LDlink package was used to calculate the linkage disequilibrium (LD) within SNPs (30). The RegulomeDB (31) tool was applied to annotate SNPs with known or predicted regulatory elements. Meta-analysis was conducted by weighting effect size estimates with the inverse of the standard errors. The SNP association's statistical significance was calculated using the $Z$-test, and a pooled $\mathrm{P}$ value $<0.05$ was considered significant.

\section{$R N A$ extraction and quantitative real-time polymerase chain reaction ( $q R T-P C R)$}

Male Balb/c mice (6-8 weeks old) were obtained from Shanghai Laboratory Animal Center, Chinese Academy of
Sciences (CAS). Mice were anesthetized by pentobarbital sodium and perfused by intracardiac injection of phosphatebuffered saline (PBS). Murine organ tissues, including the cornea, retina, heart, liver, lung, kidney, brain, and lymph nodes, were isolated. Total RNA was extracted with RNA Simple Total RNA Kit (TIANGEN, Beijing, China). The first-strand cDNA was reverse transcribed with the FastKing RT Kit (TIANGEN, Beijing, China). Quantitative real-time PCR was performed with a QuantiNova SYBR Green PCR Kit (Qiagen, Hamburg, Germany) according to the manufacturer's protocols. Primer sequences used are listed below.

Mouse glyceraldehyde 3-phosphate dehydrogenase $(G A P D H)$ gene:

Forward 5'-CATCACTGCCACCCAGAAGACTG-3', Reverse 5'-ATGCCAGTGAGCTTCCCGTTCAG-3';

Mouse STON2 gene:

Forward 5'-GTATGAGCACGCCTTCAACTCC-3', Reverse 5'- GGCAAATCTGGAAGGCACTTCC-3'.

All reactions were performed in quadruplicate, and the experiments were replicated three times independently. Relative gene expression levels were determined using the delta Ct method. Animal experiments were performed under a project license (2015044-2) granted by the Ethics Committee of the Eye and ENT Hospital of Fudan University, in compliance with the Association for Research in Vision and Ophthalmology (ARVO) statement for the Use of Animals in Ophthalmic and Vision Research.

\section{Results}

A total of 164 patients with KCTN and 239 healthy subjects were recruited in this study. The average age of patients with KCTN was $23.64 \pm 6.17$ years, and $75.6 \%$ of this cohort were male (Table 1). The healthy controls had an average 
Table 2 A summary of the three SNPs in the STON2 gene

\begin{tabular}{lccccc}
\hline \multirow{2}{*}{ SNP } & Coordinate (GRCh38.p12) & Allele & RegulomeDB score & HWE P values \\
\cline { 3 - 5 } & & & C/G & 2b (likely to affect binding) & 0.8604 \\
rs2371597* & Chr14:81407033 & Controls & 0.865 \\
rs8004137 & Chr14:81418513 & A/G & 2b (likely to affect binding) & 0.6990 & 0.7294 \\
rs8008602 & Chr14:81423827 & T/A & 2b (likely to affect binding) & 0.5767 & 0.8673 \\
\hline
\end{tabular}

*, shown as the reported SNP in the Nagahama study (23). SNP, single nucleotide polymorphisms; HWE, Hardy-Weinberg equilibrium.

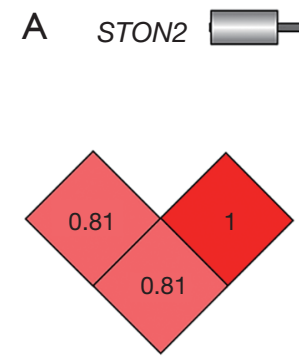

$\mathrm{CHB}$

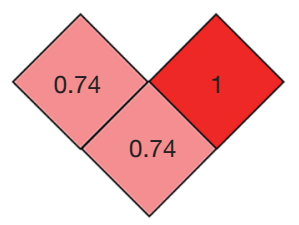

JPT

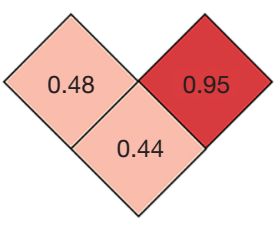

CEU

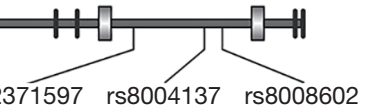

B

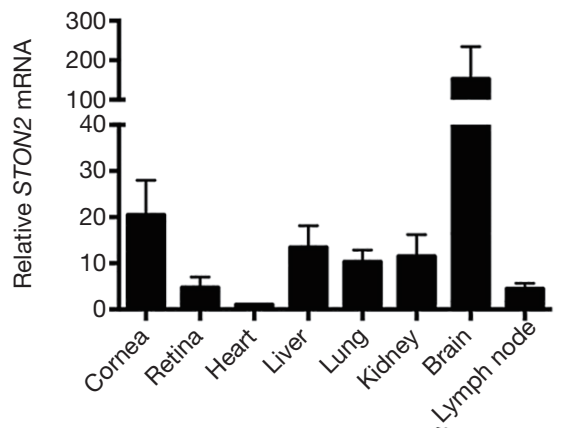

Figure $1 \mathrm{LD}$ of the three SNPs in the STON2 gene and STON2 mRNA expression in various organ tissues. (A) LD of the three SNPs in the STON2 gene, shown as pairwise $\mathrm{r}^{2}$ values in CHB (Chinese Han in Beijing), JPT (Japanese in Tokyo), CEU (Caucasian), and YRI (Yoruba in Ibadan, Nigeria), from the 1000G Project Phase 3. (B) Relative STON2 mRNA expression in various adult mouse tissues measured by qRT-PCR. Data is shown as mean \pm SD. The experiments were performed three times, and each experiment included five mice. LD, linkage disequilibrium; SNP, single nucleotide polymorphism; qRT-PCR, quantitative real-time polymerase chain reaction; SD, standard deviation.

age of $30.02 \pm 5.36$ years, and $62.7 \%$ were male. These characteristics were comparable to that of the KCTN group.

Three SNPs in the STON2 gene were genotyped. SNP rs2371597 has been shown in a GWAS to affect KCTN susceptibility in the Japanese population (23). The current study aimed to determine whether it had a similar effect on the Han Chinese population. The other two SNPs were selected based on in-silico functional annotation. Briefly, SNPs showing LD $\left(r^{2} \geq 0.8\right.$ in East Asian cohort from 1000
Genomes Project Phase 3) with rs2371597 were subjected to RegulomeDB annotation to examine if they overlapped with some known or predicted regulatory elements. Consequently, two other SNPs, namely rs8004137 and rs8008602, were selected for replication, given their predicted roles in affecting transcription factor binding (Table 2, Figure 1A).

The average genotyping call rate was $95.0 \%$ for the three genotyped SNPs, and all satisfied the Hardy-Weinberg equilibrium (HWE) in the controls (Table 2 and Table S1). 
Table 3 Association analyses of the three SNPs in the STON2 gene

\begin{tabular}{lcccccccc}
\hline SNP & Allele & MAF (case), \% MAF (control), \% & $\chi^{2}$ & P value & OR (95\% Cl) & Meta P value & Meta OR (95\% Cl) \\
\hline rs2371597 & C/G & 34.8 & 26.6 & 6.027 & 0.01409 & $1.47(1.08-2.02)$ & 0.005694 & $1.37(1.11-1.62)$ \\
rs8004137 & A/G & 30.3 & 26.6 & 1.222 & 0.2690 & $1.20(0.88-1.67)$ & - & - \\
rs8008602 & T/A & 31.2 & 27.6 & 1.198 & 0.2737 & $1.19(0.87-1.64)$ & - & - \\
\hline
\end{tabular}

95\% Cl: lower/upper bound of 95\% Cl for OR; meta-analysis was performed on association results from a previous Japanese cohort (23) and this Chinese cohort. SNP, single nucleotide polymorphisms; MAF, minor allele frequency; OR, odds ratio; Cl, confidence interval.

Table 4 Association analyses on SNP genotypes with KCTN susceptibility

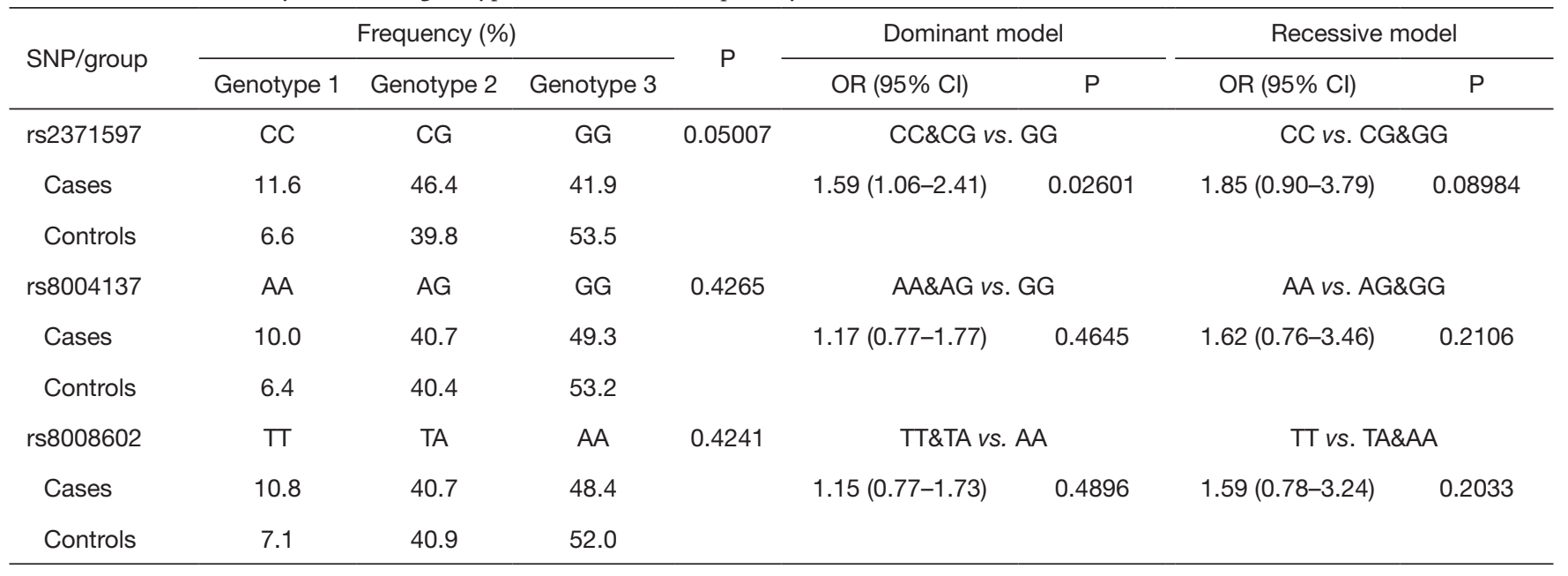

SNP, single nucleotide polymorphisms; OR, odds ratio; $\mathrm{Cl}$, confidence interval.

The association result showed that only the $\mathrm{C}$ allele of SNP rs2371597 was significantly associated with KCTN susceptibility (OR $=1.47,95 \%$ CI: 1.08 to $2.02, \mathrm{P}=0.01409$, $\mathrm{P}=0.04227$ with Bonferroni correction, Table 3). A metaanalysis on the association results of the Japanese cohort (23) and this Chinese cohort further supported the association of rs2371597 with KCTN risk (P_meta $=0.005694$, OR_meta $=1.37,95 \%$ CI: 1.11 to 1.62 ). Genotype association analysis showed that, within the dominant model, genotype CC and CG of rs2371597 revealed an OR of 1.59 (95\% CI: 1.06 to 2.41, $\mathrm{P}=0.02601$, Table 4). The association results between the STON2 gene haplotype and the risk of KCTN are listed in Table 5. The haplotype CAT was significantly associated with the risk of KCTN $(\mathrm{P}=0.04101)$. The other two SNPs allele and genotypic frequencies did not reveal substantial differences between the cases and the controls.

Furthermore, gene expression pattern analysis among different murine organ tissues showed that STON2 was widely expressed in all mouse tissues examined and presented a relatively higher expression in the cornea (Figure 1B).

\section{Discussion}

This study demonstrated the association of the STON2 locus with KCTN susceptibility in a Han Chinese population. This concurs with a previous study in a Japanese population (23), and meta-analysis data supported this observation (P_meta 0.005694, OR_meta $=1.37$, 95\% CI: 1.11 to 1.62$)$. These results support the notion that STON2 contributes to KCTN susceptibility among Asians.

Segregation analyses have suggested that KCTN is a complicated trait affected by many factors, including genes, variable penetrance, and environmental triggers (32). Although some efforts have been made (4) to explore the genetic factors contributing to KCTN risk, the understanding of KCTN genetics is still in its infancy. In contrast to other complex diseases that usually recruit over thousands of participants, the sample sizes in GWASs examining KCTN have generally been quite small, thus limiting the statistical power for detecting novel association signals. Alternatively, the involvement of the endophenotype CCT is efficient in identifying additional susceptibility genes for KCTN (21). CCT is a highly heritable 
Table 5 Results of the STON2 haplotype analysis

\begin{tabular}{lccccc}
\hline Haplotype (rs2371597/rs8004137/rs8008602) & MAF (case), \% & MAF (control), \% & $\chi^{2}$ & P value & OR (95\% Cl) \\
\hline C/A/T & 27.9 & 21.8 & 4.175 & 0.04101 & $1.46(0.89-2.32)$ \\
G/A/T & 2.9 & 4.5 & 1.088 & 0.2969 & $0.67(0.23-1.94)$ \\
C/G/A & 6.1 & 4.8 & 0.7589 & 0.3837 & $1.36(0.57-3.31)$ \\
G/G/A & 62.2 & 68.1 & 2.753 & 0.09708 & $0.79(0.50-1.18)$ \\
\hline
\end{tabular}

MAF, minor allele frequency; OR, odds ratio; $\mathrm{Cl}$, confidence interval.

quantitative trait, with heritability estimates ranging from 0.68 to $0.95(33,34)$. Thinner CCT is often observed in common ocular diseases such as KCTN (35). With such an approach, several recent GWASs have successfully identified that some of these CCT loci were also associated with KCTN susceptibility. STON2 was one such gene, and therefore it was the focus of this current study. The successful validation of the association between STON2 SNPs and KCTN risk in both the Japanese and the Han Chinese populations supports future investigations into other newly defined CCT loci and their association with KCTN susceptibility (21).

The current study demonstrated the association between STON2 and KCTN susceptibility among Asians. Interestingly, the effect size of SNP rs2371597 differed between the Chinese and the Japanese cohorts ( $\mathrm{OR}=1.47$ in the Chinese cohort, and $\mathrm{OR}=1.27$ in the Japanese cohort), which may be partially due to the different minor allele frequencies between the two cohorts $(\mathrm{C}=32.5 \%$ in the Chinese cohort and $\mathrm{C}=25.5 \%$ in the Japanese cohort). Thus, it would be of interest to further examine the contribution of STON2 SNP(s) to KCTN susceptibility in other ethnicities, such as the Caucasian population. Furthermore, three SNPs with predicted roles in affecting binding were genotyped. However, two of them did not show any substantial association with KCTN in this cohort, although some trends were detected. Herein, in-depth replication studies with larger sample size are warranted. Lastly, the relationship between genetic variants and cellular abnormalities is still unclear. A previous Japanese study showed strong expression of STON2 in basal cells compared to superficial cells in the corneal epithelium, with minimal expression in the corneal stroma and endothelium layer. Our findings also highlighted a relatively high expression of STON2 in the cornea compared to other organ tissues. Deficiencies in STON2 may increase cell vulnerability to physical damage or immunological changes, thereby affecting KCTN development via interacting with extracellular matrix modeling. However, direct biological evidence will be required to confirm this hypothesis. Future systematically functional investigations should be conducted to elucidate further the mechanisms by which susceptible variants affect STON2 gene function and finally contribute to KCTN development.

In conclusion, this study explored the association between SNPs in the STON2 gene and KCTN susceptibility in a Han Chinese population. The results verified that the STON2 gene contributes to KCTN susceptibility. This study provided novel insights related to the genetic basis underlying KCTN pathogenesis, which will pave the way for future advances in prevention and treatment.

\section{Acknowledgments}

Funding: The authors were sponsored by the National Natural Science Foundation of China (81870630, 81700806). The sponsor or funding organization had no role in the design or conduct of this research.

\section{Footnote}

Reporting Checklist: The authors have completed the MDAR reporting checklist. Available at http://dx.doi.org/10.21037/ atm-20-6654

Data Sharing Statement: Available at http://dx.doi. org/10.21037/atm-20-6654

Conflicts of Interest: All authors have completed the ICMJE uniform disclosure form (available at http://dx.doi. org/10.21037/atm-20-6654). The authors have no conflicts of interest to declare.

Ethical Statement: The authors are accountable for all aspects of the work in ensuring that questions related to the accuracy or integrity of any part of the work are appropriately investigated and resolved. The study was 
conducted in accordance with the Declaration of Helsinki (as revised in 2013). The study was approved by the Ethics Committee of the Eye and ENT Hospital of Fudan University (2015044-1) and informed consent was obtained from all participants. Animal experiments were performed under a project license (2015044-2) granted by the Ethics Committee of the Eye and ENT Hospital of Fudan University, in compliance with the ARVO statement for the Use of Animals in Ophthalmic and Vision Research.

Open Access Statement: This is an Open Access article distributed in accordance with the Creative Commons Attribution-NonCommercial-NoDerivs 4.0 International License (CC BY-NC-ND 4.0), which permits the noncommercial replication and distribution of the article with the strict proviso that no changes or edits are made and the original work is properly cited (including links to both the formal publication through the relevant DOI and the license). See: https://creativecommons.org/licenses/by-nc-nd/4.0/.

\section{References}

1. Faria-Correia F, Luz A, Ambrosio R. Managing corneal ectasia prior to keratoplasty. Expert Rev Ophthalmo 2015;10:33-48.

2. Rabinowitz YS. Keratoconus. Surv Ophthalmol 1998;42:297-319.

3. Kok YO, Tan GF, Loon SC. Review: keratoconus in Asia. Cornea 2012;31:581-93.

4. Karolak JA, Gajecka M. Genomic strategies to understand causes of keratoconus. Mol Genet Genomics 2017;292:251-69.

5. Arnal E, Peris-Martinez C, Menezo JL, et al. Oxidative stress in keratoconus? Invest Ophthalmol Vis Sci 2011;52:8592-7.

6. Steahly LP. Keratoconus following contact lens wear. Ann Ophthalmol 1978;10:1177-9.

7. Bawazeer AM, Hodge WG, Lorimer B. Atopy and keratoconus: a multivariate analysis. Br J Ophthalmol 2000;84:834-6.

8. McMonnies CW. Mechanisms of rubbing-related corneal trauma in keratoconus. Cornea 2009;28:607-15.

9. Burdon KP, Vincent AL. Insights into keratoconus from a genetic perspective. Clin Exp Optom 2013;96:146-54.

10. Naderan M, Rajabi MT, Zarrinbakhsh P, et al. Association between Family History and Keratoconus Severity. Curr Eye Res 2016;41:1414-8.

11. Tuft SJ, Hassan H, George S, et al. Keratoconus in 18 pairs of twins. Acta Ophthalmol 2012;90:e482-6.

12. Mackey DA, Hewitt AW. Genome-wide association study success in ophthalmology. Curr Opin Ophthalmol 2014;25:386-93.

13. Li X, Bykhovskaya Y, Tang YG, et al. An association between the calpastatin (CAST) gene and keratoconus. Cornea 2013;32:696-701.

14. Li X, Bykhovskaya Y, Canedo AL, et al. Genetic association of COL5A1 variants in keratoconus patients suggests a complex connection between corneal thinning and keratoconus. Invest Ophthalmol Vis Sci 2013;54:2696-704.

15. Li X, Bykhovskaya $Y$, Haritunians T, et al. A genome-wide association study identifies a potential novel gene locus for keratoconus, one of the commonest causes for corneal transplantation in developed countries. Hum Mol Genet 2012;21:421-9.

16. Cuellar-Partida G, Springelkamp H, Lucas SE, et al. WNT10A exonic variant increases the risk of keratoconus by decreasing corneal thickness. Hum Mol Genet 2015;24:5060-8.

17. De Bonis P, Laborante A, Pizzicoli C, et al. Mutational screening of VSX1, SPARC, SOD1, LOX, and TIMP3 in keratoconus. Mol Vis 2011;17:2482-94.

18. Wang $\mathrm{Y}$, Jin T, Zhang $\mathrm{X}$, et al. Common single nucleotide polymorphisms and keratoconus in the Han Chinese population. Ophthalmic Genet 2013;34:160-6.

19. Czugala M, Karolak JA, Nowak DM, et al. Novel mutation and three other sequence variants segregating with phenotype at keratoconus $13 \mathrm{q} 32$ susceptibility locus. Eur J Hum Genet 2012;20:389-97.

20. Bykhovskaya Y, Li X, Epifantseva I, et al. Variation in the lysyl oxidase (LOX) gene is associated with keratoconus in family-based and case-control studies. Invest Ophthalmol Vis Sci 2012;53:4152-7.

21. Iglesias AI, Mishra A, Vitart V, et al. Cross-ancestry genome-wide association analysis of corneal thickness strengthens link between complex and Mendelian eye diseases. Nat Commun 2018;9:1864.

22. Lu Y, Vitart V, Burdon KP, et al. Genome-wide association analyses identify multiple loci associated with central corneal thickness and keratoconus. Nat Genet 2013;45:155-63.

23. Hosoda Y, Miyake M, Meguro A, et al. Keratoconussusceptibility gene identification by corneal thickness genome-wide association study and artificial intelligence IBM Watson. Commun Biol 2020;3:410.

24. Hao XD, Chen P, Chen ZL, et al. Evaluating the Association between Keratoconus and Reported Genetic 
Page 8 of 8

Loci in a Han Chinese Population. Ophthalmic Genet 2015;36:132-6.

25. Wang $\mathrm{Y}$, Wei $\mathrm{W}$, Zhang C, et al. Association of Interleukin-1 Gene Single Nucleotide Polymorphisms with Keratoconus in Chinese Han Population. Curr Eye Res 2016;41:630-5.

26. Wang YM, Ma L, Lu SY, et al. Analysis of multiple genetic loci reveals MPDZ-NF1B rs1324183 as a putative genetic marker for keratoconus. Br J Ophthalmol 2018;102:1736-41.

27. Zhang J, Wu D, Li Y, et al. Evaluating the association between calpastatin (CAST) gene and keratoconus in the Han Chinese population. Gene 2018;653:10-3.

28. Martina JA, Bonangelino CJ, Aguilar RC, et al. Stonin 2: an adaptor-like protein that interacts with components of the endocytic machinery. J Cell Biol 2001;153:1111-20.

29. Purcell S, Neale B, Todd-Brown K, et al. PLINK: a tool set for whole-genome association and population-based linkage analyses. Am J Hum Genet 2007;81:559-75.

Cite this article as: Zhang J, Li Y, Dai Y, Xu J. Evaluating the association between single nucleotide polymorphisms in the stonin 2 (STON2) gene and keratoconus in a Han Chinese population. Ann Transl Med 2021;9(8):616. doi: 10.21037/atm20-6654

\section{Zhang et al. Association between STON2 and KCTN in Han Chinese}

30. Machiela MJ, Chanock SJ. LDlink: a web-based application for exploring population-specific haplotype structure and linking correlated alleles of possible functional variants. Bioinformatics 2015;31:3555-7.

31. Boyle AP, Hong EL, Hariharan M, et al. Annotation of functional variation in personal genomes using RegulomeDB. Genome Res 2012;22:1790-7.

32. Kriszt A, Losonczy G, Berta A, et al. Segregation analysis suggests that keratoconus is a complex non-mendelian disease. Acta Ophthalmol 2014;92:e562-8.

33. Dimasi DP, Burdon KP, Craig JE. The genetics of central corneal thickness. Br J Ophthalmol 2010;94:971-6.

34. Toh T, Liew SH, MacKinnon JR, et al. Central corneal thickness is highly heritable: the twin eye studies. Invest Ophthalmol Vis Sci 2005;46:3718-22.

35. Steele TM, Fabinyi DC, Couper TA, et al. Prevalence of Orbscan II corneal abnormalities in relatives of patients with keratoconus. Clin Exp Ophthalmol 2008;36:824-30. 


\section{Supplementary}

Table S1 Individual genotype for SNPs rs2371597, rs8004137, rs8008602 of the included 164 cases and 239 controls

\begin{tabular}{|c|c|c|c|c|c|c|c|}
\hline \multirow{2}{*}{ Sample ID } & \multirow{2}{*}{ Case/control } & \multicolumn{2}{|c|}{ rs2371597 } & \multicolumn{2}{|c|}{ rs8004137 } & \multicolumn{2}{|c|}{ rs8008602 } \\
\hline & & Allele 1 & Allele 2 & Allele 1 & Allele 2 & Allele 1 & Allele 2 \\
\hline $11 \mathrm{~F}$ & Control & C & $G$ & A & G & $T$ & A \\
\hline $11 \mathrm{M}$ & Control & G & G & G & G & A & A \\
\hline $12 \mathrm{~F}$ & Control & C & G & A & G & $\mathrm{T}$ & A \\
\hline $12 M$ & Control & G & G & G & G & A & A \\
\hline $13 \mathrm{M}$ & Control & C & G & A & G & $\mathrm{T}$ & A \\
\hline $14 \mathrm{~F}$ & Control & G & G & A & G & $\mathrm{T}$ & A \\
\hline $14 M$ & Control & C & C & A & G & $\mathrm{T}$ & A \\
\hline $15 \mathrm{~F}$ & Control & G & G & 0 & 0 & 0 & 0 \\
\hline $15 \mathrm{M}$ & Control & G & G & G & G & A & A \\
\hline $16 \mathrm{~F}$ & Control & G & G & G & G & A & A \\
\hline $16 \mathrm{M}$ & Control & G & G & G & G & A & A \\
\hline $18 \mathrm{~F}$ & Control & C & C & A & G & $\mathrm{T}$ & A \\
\hline $18 \mathrm{M}$ & Control & G & G & G & G & A & A \\
\hline $19 \mathrm{~F}$ & Control & G & G & G & G & A & A \\
\hline $19 M$ & Control & C & C & A & G & $\mathrm{T}$ & A \\
\hline $1 \mathrm{~F}$ & Control & C & G & 0 & 0 & $\mathrm{~T}$ & A \\
\hline $1 \mathrm{M}$ & Control & C & G & G & G & $\mathrm{T}$ & A \\
\hline $20 \mathrm{~F}$ & Control & G & G & G & G & A & A \\
\hline $20 \mathrm{M}$ & Control & C & G & G & G & A & A \\
\hline $21 \mathrm{~F}$ & Control & C & G & A & G & $\mathrm{T}$ & A \\
\hline $21 M$ & Control & G & G & 0 & 0 & 0 & 0 \\
\hline 22M & Control & C & G & G & G & A & A \\
\hline $23 \mathrm{~F}$ & Control & G & G & G & G & A & A \\
\hline $23 \mathrm{M}$ & Control & G & G & G & G & A & A \\
\hline $24 \mathrm{~F}$ & Control & C & G & A & G & $\mathrm{T}$ & A \\
\hline $24 M$ & Control & C & G & G & G & $\mathrm{T}$ & A \\
\hline $25 \mathrm{~F}$ & Control & G & G & G & G & A & A \\
\hline $25 \mathrm{M}$ & Control & G & G & G & G & A & A \\
\hline $26 \mathrm{~F}$ & Control & C & C & A & G & $\mathrm{T}$ & A \\
\hline $26 \mathrm{M}$ & Control & G & G & G & G & A & A \\
\hline $27 \mathrm{~F}$ & Control & G & G & 0 & 0 & 0 & 0 \\
\hline $27 \mathrm{M}$ & Control & G & G & G & G & A & A \\
\hline $28 \mathrm{~F}$ & Control & G & G & G & G & A & A \\
\hline $28 \mathrm{M}$ & Control & G & G & G & G & A & A \\
\hline
\end{tabular}

Table S1 (continued) 
Table S1 (continued)

\begin{tabular}{|c|c|c|c|c|c|c|c|}
\hline \multirow{2}{*}{ Sample ID } & \multirow{2}{*}{ Case/control } & \multicolumn{2}{|c|}{ rs2371597 } & \multicolumn{2}{|c|}{ rs8004137 } & \multicolumn{2}{|c|}{ rs8008602 } \\
\hline & & Allele 1 & Allele 2 & Allele 1 & Allele 2 & Allele 1 & Allele 2 \\
\hline $29 \mathrm{~F}$ & Control & C & G & A & G & $T$ & A \\
\hline $2 \mathrm{~F}$ & Control & $\mathrm{G}$ & G & G & G & A & A \\
\hline $2 \mathrm{M}$ & Control & C & G & A & G & $\mathrm{T}$ & A \\
\hline $30 \mathrm{~F}$ & Control & G & G & 0 & 0 & A & A \\
\hline $30 \mathrm{M}$ & Control & G & G & G & G & A & A \\
\hline $31 \mathrm{~F}$ & Control & C & G & A & A & A & A \\
\hline $31 \mathrm{M}$ & Control & G & G & A & A & $\mathrm{T}$ & $\mathrm{T}$ \\
\hline $33 \mathrm{~F}$ & Control & C & C & A & A & T & T \\
\hline $33 M$ & Control & C & G & A & G & $\mathrm{T}$ & A \\
\hline $36 \mathrm{~F}$ & Control & C & G & A & A & $\mathrm{T}$ & $\mathrm{T}$ \\
\hline $36 \mathrm{M}$ & Control & C & G & A & G & $\mathrm{T}$ & A \\
\hline $37 \mathrm{~F}$ & Control & C & C & G & G & $\mathrm{T}$ & $\mathrm{T}$ \\
\hline $37 \mathrm{M}$ & Control & G & G & G & G & $\mathrm{T}$ & $T$ \\
\hline $38 \mathrm{~F}$ & Control & 0 & 0 & 0 & 0 & A & A \\
\hline $38 \mathrm{M}$ & Control & G & G & G & G & A & A \\
\hline $39 F$ & Control & 0 & 0 & 0 & 0 & $\mathrm{~T}$ & A \\
\hline $39 M$ & Control & $\mathrm{G}$ & G & G & G & A & A \\
\hline $3 F$ & Control & G & G & G & G & A & A \\
\hline $3 M$ & Control & G & G & G & G & A & A \\
\hline $40 \mathrm{~F}$ & Control & G & G & A & G & $\mathrm{T}$ & $\mathrm{T}$ \\
\hline $40 \mathrm{M}$ & Control & C & G & A & G & T & A \\
\hline $41 \mathrm{~F}$ & Control & G & G & G & G & A & A \\
\hline $41 \mathrm{M}$ & Control & C & G & A & G & $\mathrm{T}$ & A \\
\hline $42 \mathrm{~F}$ & Control & G & G & G & G & A & A \\
\hline $42 \mathrm{M}$ & Control & C & G & A & G & $\mathrm{T}$ & A \\
\hline $43 \mathrm{~F}$ & Control & $\mathrm{G}$ & G & G & G & A & A \\
\hline $43 M$ & Control & G & G & G & G & A & A \\
\hline $44 \mathrm{~F}$ & Control & G & G & G & G & A & A \\
\hline $44 M$ & Control & G & G & G & G & A & A \\
\hline $45 \mathrm{~F}$ & Control & C & G & A & G & 0 & 0 \\
\hline $45 \mathrm{M}$ & Control & C & G & A & G & $\mathrm{T}$ & A \\
\hline $46 \mathrm{~F}$ & Control & G & G & G & G & A & A \\
\hline $46 \mathrm{M}$ & Control & G & G & G & G & A & A \\
\hline $47 \mathrm{~F}$ & Control & C & G & A & G & T & A \\
\hline
\end{tabular}

Table S1 (continued) 
Table S1 (continued)

\begin{tabular}{|c|c|c|c|c|c|c|c|}
\hline \multirow{2}{*}{ Sample ID } & \multirow{2}{*}{ Case/control } & \multicolumn{2}{|c|}{ rs2371597 } & \multicolumn{2}{|c|}{ rs8004137 } & \multicolumn{2}{|c|}{ rs8008602 } \\
\hline & & Allele 1 & Allele 2 & Allele 1 & Allele 2 & Allele 1 & Allele 2 \\
\hline $47 \mathrm{M}$ & Control & G & G & G & G & A & A \\
\hline $48 \mathrm{~F}$ & Control & C & G & A & G & $\begin{array}{l}\mathrm{T} \\
\end{array}$ & A \\
\hline $48 \mathrm{M}$ & Control & G & G & G & G & A & A \\
\hline $4 \mathrm{~F}$ & Control & C & G & A & G & $\mathrm{T}$ & A \\
\hline $4 \mathrm{M}$ & Control & C & G & A & G & $\mathrm{T}$ & A \\
\hline $50 \mathrm{~F}$ & Control & C & G & A & G & $\mathrm{T}$ & A \\
\hline $50 \mathrm{M}$ & Control & G & G & G & G & A & A \\
\hline $51 \mathrm{~F}$ & Control & C & G & G & G & A & A \\
\hline $51 \mathrm{M}$ & Control & C & G & G & G & A & A \\
\hline $52 \mathrm{~F}$ & Control & G & G & G & G & A & A \\
\hline $52 \mathrm{M}$ & Control & C & G & A & G & $\mathrm{T}$ & A \\
\hline $54 \mathrm{~F}$ & Control & G & G & 0 & 0 & A & A \\
\hline $54 \mathrm{M}$ & Control & G & G & G & G & A & A \\
\hline $55 \mathrm{~F}$ & Control & G & G & G & G & A & A \\
\hline $55 \mathrm{M}$ & Control & G & G & G & G & A & A \\
\hline $56 \mathrm{M}$ & Control & G & G & G & G & A & A \\
\hline $58 \mathrm{~F}$ & Control & G & G & G & G & A & A \\
\hline $58 \mathrm{M}$ & Control & C & G & A & G & $\mathrm{T}$ & A \\
\hline $59 \mathrm{~F}$ & Control & C & G & A & G & $\mathrm{T}$ & A \\
\hline $59 M$ & Control & G & G & G & G & A & A \\
\hline $5 F$ & Control & G & G & G & G & A & A \\
\hline $5 \mathrm{M}$ & Control & G & G & G & G & A & A \\
\hline $60 \mathrm{M}$ & Control & G & G & 0 & 0 & A & A \\
\hline $61 \mathrm{~F}$ & Control & C & G & G & G & A & A \\
\hline $61 \mathrm{M}$ & Control & G & G & G & G & A & A \\
\hline $62 \mathrm{~F}$ & Control & C & C & A & A & $\mathrm{T}$ & $\mathrm{T}$ \\
\hline $62 \mathrm{M}$ & Control & C & G & A & G & $\mathrm{T}$ & A \\
\hline $66 \mathrm{~F}$ & Control & G & G & G & G & A & A \\
\hline $66 \mathrm{M}$ & Control & G & G & A & G & $\mathrm{T}$ & A \\
\hline $67 \mathrm{~F}$ & Control & C & G & G & G & A & A \\
\hline $67 \mathrm{M}$ & Control & G & G & G & G & A & A \\
\hline $68 \mathrm{~F}$ & Control & G & G & G & G & A & A \\
\hline $68 \mathrm{M}$ & Control & G & G & G & G & A & A \\
\hline $69 \mathrm{~F}$ & Control & G & G & G & G & A & A \\
\hline
\end{tabular}

Table S1 (continued) 
Table S1 (continued)

\begin{tabular}{|c|c|c|c|c|c|c|c|}
\hline \multirow{2}{*}{ Sample ID } & \multirow{2}{*}{ Case/control } & \multicolumn{2}{|c|}{ rs2371597 } & \multicolumn{2}{|c|}{ rs 8004137} & \multicolumn{2}{|c|}{ rs8008602 } \\
\hline & & Allele 1 & Allele 2 & Allele 1 & Allele 2 & Allele 1 & Allele 2 \\
\hline $69 M$ & Control & G & G & G & G & A & A \\
\hline $6 \mathrm{~F}$ & Control & C & G & A & A & T & T \\
\hline $6 \mathrm{M}$ & Control & C & G & A & G & $\mathrm{T}$ & A \\
\hline $70 F$ & Control & C & G & A & G & $\mathrm{T}$ & A \\
\hline $70 \mathrm{M}$ & Control & C & G & A & G & $\mathrm{T}$ & A \\
\hline $71 \mathrm{~F}$ & Control & G & G & G & G & A & A \\
\hline $71 \mathrm{M}$ & Control & C & C & A & A & $\mathrm{T}$ & $\mathrm{T}$ \\
\hline $72 \mathrm{~F}$ & Control & $\mathrm{G}$ & G & $\mathrm{G}$ & G & A & A \\
\hline $72 M$ & Control & C & C & A & G & $\mathrm{T}$ & A \\
\hline $73 F$ & Control & C & G & A & G & $\mathrm{T}$ & A \\
\hline $73 M$ & Control & G & G & G & G & A & A \\
\hline $74 \mathrm{~F}$ & Control & G & G & G & G & A & A \\
\hline $74 M$ & Control & G & G & A & G & $\mathrm{T}$ & A \\
\hline $75 \mathrm{~F}$ & Control & C & G & A & G & $\mathrm{T}$ & A \\
\hline $75 \mathrm{M}$ & Control & C & G & G & G & A & A \\
\hline $76 \mathrm{~F}$ & Control & C & G & A & G & $\mathrm{T}$ & A \\
\hline $76 \mathrm{M}$ & Control & $\mathrm{G}$ & G & $\mathrm{G}$ & G & A & A \\
\hline $77 \mathrm{~F}$ & Control & C & G & A & G & $\mathrm{T}$ & A \\
\hline $77 \mathrm{M}$ & Control & G & G & G & G & A & A \\
\hline $78 \mathrm{~F}$ & Control & C & G & G & G & A & A \\
\hline $78 \mathrm{M}$ & Control & C & G & A & G & T & A \\
\hline $79 F$ & Control & G & G & G & G & A & A \\
\hline $79 M$ & Control & G & G & G & G & A & A \\
\hline $7 F$ & Control & C & G & A & G & $\mathrm{T}$ & A \\
\hline $7 \mathrm{M}$ & Control & C & G & A & G & $\mathrm{T}$ & A \\
\hline $80 \mathrm{~F}$ & Control & C & G & A & G & T & A \\
\hline $80 \mathrm{M}$ & Control & G & G & G & G & A & A \\
\hline $81 \mathrm{~F}$ & Control & C & C & A & A & $\mathrm{T}$ & $\mathrm{T}$ \\
\hline $81 M$ & Control & G & G & A & G & $\mathrm{T}$ & A \\
\hline $82 \mathrm{~F}$ & Control & G & G & A & G & $\mathrm{T}$ & A \\
\hline $82 \mathrm{M}$ & Control & C & G & A & G & $\mathrm{T}$ & A \\
\hline $8 \mathrm{~F}$ & Control & C & G & A & G & $\mathrm{T}$ & A \\
\hline $9 \mathrm{~F}$ & Control & G & G & 0 & 0 & A & A \\
\hline $9 M$ & Control & C & G & A & G & T & A \\
\hline
\end{tabular}

Table S1 (continued) 
Table S1 (continued)

\begin{tabular}{|c|c|c|c|c|c|c|c|}
\hline \multirow{2}{*}{ Sample ID } & \multirow{2}{*}{ Case/control } & \multicolumn{2}{|c|}{ rs2371597 } & \multicolumn{2}{|c|}{ rs8004137 } & \multicolumn{2}{|c|}{ rs8008602 } \\
\hline & & Allele 1 & Allele 2 & Allele 1 & Allele 2 & Allele 1 & Allele 2 \\
\hline CD10F & Control & C & G & A & G & $\mathrm{T}$ & A \\
\hline CD10M & Control & G & G & G & G & A & A \\
\hline CD7F & Control & G & G & 0 & 0 & A & A \\
\hline CD7M & Control & C & G & A & G & $\mathrm{T}$ & A \\
\hline CD81F & Control & G & G & G & G & A & A \\
\hline CD81M & Control & C & C & A & A & $\mathrm{T}$ & $\mathrm{T}$ \\
\hline HC001 & Control & 0 & 0 & 0 & 0 & T & A \\
\hline $\mathrm{HCOO2}$ & Control & 0 & 0 & 0 & 0 & 0 & 0 \\
\hline $\mathrm{HCOO3}$ & Control & G & G & A & G & $\mathrm{T}$ & A \\
\hline $\mathrm{HCOO} 4$ & Control & G & G & G & G & A & A \\
\hline HCOO5 & Control & G & G & G & G & A & A \\
\hline HCO06 & Control & C & G & A & A & T & T \\
\hline $\mathrm{HCOO7}$ & Control & C & G & A & G & T & A \\
\hline HC008 & Control & C & G & A & G & T & A \\
\hline HCOO9 & Control & G & G & A & G & $\mathrm{T}$ & A \\
\hline HC010 & Control & C & G & G & G & $\mathrm{T}$ & A \\
\hline HC011 & Control & G & G & G & G & A & A \\
\hline $\mathrm{HC} 012$ & Control & G & G & G & G & A & A \\
\hline $\mathrm{HC} 013$ & Control & G & G & G & G & A & A \\
\hline $\mathrm{HC} 014$ & Control & G & G & G & G & A & A \\
\hline HC015 & Control & C & G & A & G & $\mathrm{T}$ & A \\
\hline HC016 & Control & G & G & G & G & A & A \\
\hline $\mathrm{HC} 017$ & Control & C & G & G & G & $\mathrm{T}$ & A \\
\hline HC018 & Control & C & G & G & G & A & A \\
\hline HC019 & Control & G & G & G & G & A & A \\
\hline $\mathrm{HCO} 20$ & Control & C & G & A & G & $\mathrm{T}$ & A \\
\hline $\mathrm{HC} 021$ & Control & C & G & A & G & $\mathrm{T}$ & A \\
\hline HCO22 & Control & G & G & $\mathrm{G}$ & $\mathrm{G}$ & A & A \\
\hline $\mathrm{HCO} 23$ & Control & C & G & A & G & $T$ & A \\
\hline $\mathrm{HCO} 4$ & Control & G & G & 0 & 0 & A & A \\
\hline HCO25 & Control & C & G & A & A & $T$ & $\mathrm{~T}$ \\
\hline HC026 & Control & C & G & A & G & $\mathrm{T}$ & A \\
\hline $\mathrm{HC} 027$ & Control & C & C & A & A & $\mathrm{T}$ & $\mathrm{T}$ \\
\hline $\mathrm{HCO} 8$ & Control & G & G & G & G & A & A \\
\hline
\end{tabular}

Table S1 (continued) 
Table S1 (continued)

\begin{tabular}{|c|c|c|c|c|c|c|c|}
\hline \multirow{2}{*}{ Sample ID } & \multirow{2}{*}{ Case/control } & \multicolumn{2}{|c|}{ rs2371597 } & \multicolumn{2}{|c|}{ rs8004137 } & \multicolumn{2}{|c|}{ rs8008602 } \\
\hline & & Allele 1 & Allele 2 & Allele 1 & Allele 2 & Allele 1 & Allele 2 \\
\hline $\mathrm{HCO} 29$ & Control & C & G & A & G & $\mathrm{T}$ & A \\
\hline $\mathrm{HCO3O}$ & Control & C & G & A & G & T & A \\
\hline $\mathrm{HCO} 31$ & Control & C & G & A & G & $\mathrm{T}$ & A \\
\hline $\mathrm{HCO} 32$ & Control & C & G & G & G & A & A \\
\hline $\mathrm{HCO} 33$ & Control & G & G & G & G & A & A \\
\hline $\mathrm{HCO} 34$ & Control & G & G & G & G & A & A \\
\hline HCO35 & Control & G & G & G & G & A & A \\
\hline HC036 & Control & G & G & G & G & A & A \\
\hline $\mathrm{HCO} 37$ & Control & G & G & G & G & A & A \\
\hline $\mathrm{HCO38}$ & Control & G & G & G & G & A & A \\
\hline HCO39 & Control & G & G & G & G & A & A \\
\hline $\mathrm{HCO} 40$ & Control & G & G & A & G & T & A \\
\hline $\mathrm{HC} 041$ & Control & G & G & G & G & A & A \\
\hline $\mathrm{HCO} 42$ & Control & G & G & G & G & A & A \\
\hline $\mathrm{HCO} 43$ & Control & 0 & 0 & 0 & 0 & 0 & 0 \\
\hline $\mathrm{HCO} 44$ & Control & C & C & A & A & $\mathrm{T}$ & $\mathrm{T}$ \\
\hline $\mathrm{HCO45}$ & Control & G & G & G & G & A & A \\
\hline $\mathrm{HCO} 46$ & Control & 0 & 0 & 0 & 0 & 0 & 0 \\
\hline $\mathrm{HC} 047$ & Control & G & G & G & G & A & A \\
\hline $\mathrm{HCO} 48$ & Control & C & G & A & G & T & A \\
\hline HC049 & Control & 0 & 0 & 0 & 0 & 0 & 0 \\
\hline HC050 & Control & 0 & 0 & A & G & 0 & 0 \\
\hline HC051 & Control & G & G & A & G & $\mathrm{T}$ & A \\
\hline HC052 & Control & C & G & A & G & $\mathrm{T}$ & A \\
\hline $\mathrm{HCO53}$ & Control & G & G & G & G & A & A \\
\hline $\mathrm{HCO54}$ & Control & G & G & G & G & A & A \\
\hline HC055 & Control & C & G & G & G & A & A \\
\hline HC056 & Control & G & G & $\mathrm{G}$ & $\mathrm{G}$ & A & A \\
\hline $\mathrm{HC} 057$ & Control & C & G & A & G & $T$ & A \\
\hline HC058 & Control & G & G & G & G & A & A \\
\hline HC059 & Control & G & G & G & G & A & A \\
\hline HC060 & Control & G & G & G & G & A & A \\
\hline HC061 & Control & G & G & G & G & A & A \\
\hline HC062 & Control & C & G & A & G & T & A \\
\hline
\end{tabular}

Table S1 (continued) 
Table S1 (continued)

\begin{tabular}{|c|c|c|c|c|c|c|c|}
\hline \multirow{2}{*}{ Sample ID } & \multirow{2}{*}{ Case/control } & \multicolumn{2}{|c|}{ rs2371597 } & \multicolumn{2}{|c|}{ rs8004137 } & \multicolumn{2}{|c|}{ rs8008602 } \\
\hline & & Allele 1 & Allele 2 & Allele 1 & Allele 2 & Allele 1 & Allele 2 \\
\hline HC063 & Control & C & G & A & G & $\mathrm{T}$ & A \\
\hline HC064 & Control & C & G & A & G & T & A \\
\hline HCO65 & Control & G & G & G & G & A & A \\
\hline HC066 & Control & C & C & A & G & $\mathrm{T}$ & A \\
\hline $\mathrm{HC} 067$ & Control & G & G & G & G & A & A \\
\hline $\mathrm{HC} 068$ & Control & G & G & G & G & A & A \\
\hline HC069 & Control & C & C & A & A & $\mathrm{T}$ & T \\
\hline HCO70 & Control & G & G & G & G & A & A \\
\hline $\mathrm{HC} 071$ & Control & C & G & G & G & A & A \\
\hline HCO72 & Control & G & G & A & G & T & A \\
\hline $\mathrm{HCO} 33$ & Control & G & G & G & G & A & A \\
\hline $\mathrm{HCO} 44$ & Control & G & G & G & G & A & A \\
\hline $\mathrm{HCO} 075$ & Control & G & G & G & G & 0 & 0 \\
\hline HCO76 & Control & C & G & G & G & A & A \\
\hline $\mathrm{HCO} 077$ & Control & G & G & A & G & $\mathrm{T}$ & A \\
\hline $\mathrm{HCO78}$ & Control & C & G & A & G & $\mathrm{T}$ & A \\
\hline HCO79 & Control & C & G & A & G & $T$ & A \\
\hline $\mathrm{HCO80}$ & Control & G & G & A & G & $\mathrm{T}$ & A \\
\hline HC081 & Control & C & G & A & G & $\mathrm{T}$ & A \\
\hline HC082 & Control & C & G & G & G & A & A \\
\hline HC083 & Control & C & G & A & G & $\mathrm{T}$ & A \\
\hline $\mathrm{HCO} 84$ & Control & C & G & A & G & $\mathrm{T}$ & A \\
\hline HC085 & Control & C & G & A & G & $\mathrm{T}$ & A \\
\hline HC086 & Control & G & G & G & G & A & A \\
\hline K1 & Case & C & G & A & G & $\mathrm{T}$ & A \\
\hline K10 & Case & C & G & A & G & $T$ & A \\
\hline K2 & Case & C & G & A & G & $\mathrm{T}$ & A \\
\hline K3 & Case & C & G & A & G & $\mathrm{T}$ & A \\
\hline K4 & Case & C & G & A & G & $\mathrm{T}$ & A \\
\hline K5 & Case & C & G & A & G & $\mathrm{T}$ & A \\
\hline K6 & Case & 0 & 0 & 0 & 0 & 0 & 0 \\
\hline K7 & Case & C & G & A & G & $\mathrm{T}$ & A \\
\hline K8 & Case & C & G & 0 & 0 & 0 & 0 \\
\hline K9 & Case & G & G & 0 & 0 & 0 & 0 \\
\hline
\end{tabular}

Table S1 (continued) 
Table S1 (continued)

\begin{tabular}{|c|c|c|c|c|c|c|c|}
\hline \multirow{2}{*}{ Sample ID } & \multirow{2}{*}{ Case/control } & \multicolumn{2}{|c|}{ rs2371597 } & \multicolumn{2}{|c|}{ rs8004137 } & \multicolumn{2}{|c|}{ rs8008602 } \\
\hline & & Allele 1 & Allele 2 & Allele 1 & Allele 2 & Allele 1 & Allele 2 \\
\hline KC001 & Case & C & G & A & G & $\mathrm{T}$ & A \\
\hline KC002 & Case & G & G & G & G & A & A \\
\hline KC003 & Case & C & G & A & G & $\mathrm{T}$ & A \\
\hline KCOO4 & Case & C & G & A & G & T & A \\
\hline KC005 & Case & G & G & G & G & A & A \\
\hline KC006 & Case & G & G & A & G & $\mathrm{T}$ & A \\
\hline KC007 & Case & C & G & A & G & T & A \\
\hline KC008 & Case & G & G & G & G & A & A \\
\hline KC009 & Case & C & G & A & G & T & A \\
\hline KC010 & Case & G & G & G & G & A & A \\
\hline KC011 & Case & C & C & A & A & T & $\mathrm{T}$ \\
\hline KC012 & Case & C & G & G & G & A & A \\
\hline KC013 & Case & C & G & G & G & A & A \\
\hline KC014 & Case & G & G & G & G & A & A \\
\hline KC015 & Case & G & G & G & G & A & A \\
\hline KC016 & Case & G & G & G & G & A & A \\
\hline KC017 & Case & G & G & G & G & A & A \\
\hline KC018 & Case & C & G & A & G & $\mathrm{T}$ & A \\
\hline KC019 & Case & C & C & A & A & T & $\mathrm{T}$ \\
\hline KC020 & Case & G & G & G & G & A & A \\
\hline KC021 & Case & G & G & G & G & A & A \\
\hline KC022 & Case & G & G & A & G & $\mathrm{T}$ & A \\
\hline KC023 & Case & C & C & A & G & $\mathrm{T}$ & A \\
\hline KC024 & Case & C & C & A & A & $\mathrm{T}$ & $\mathrm{T}$ \\
\hline KC025 & Case & C & G & A & G & $\mathrm{T}$ & A \\
\hline KC026 & Case & G & G & G & G & A & A \\
\hline KC027 & Case & C & C & 0 & 0 & $\mathrm{~T}$ & $\mathrm{~T}$ \\
\hline KC028 & Case & C & G & A & $\mathrm{G}$ & $\mathrm{T}$ & A \\
\hline KC029 & Case & C & G & A & A & $T$ & $\mathrm{~T}$ \\
\hline KC030 & Case & G & G & G & G & A & A \\
\hline KC031 & Case & C & G & A & G & $T$ & A \\
\hline KC032 & Case & C & G & A & A & $\mathrm{T}$ & $\mathrm{T}$ \\
\hline KC033 & Case & G & G & G & G & A & A \\
\hline KC034 & Case & C & G & A & G & T & A \\
\hline
\end{tabular}

Table S1 (continued) 
Table S1 (continued)

\begin{tabular}{|c|c|c|c|c|c|c|c|}
\hline \multirow{2}{*}{ Sample ID } & \multirow{2}{*}{ Case/control } & \multicolumn{2}{|c|}{ rs2371597 } & \multicolumn{2}{|c|}{ rs8004137 } & \multicolumn{2}{|c|}{ rs8008602 } \\
\hline & & Allele 1 & Allele 2 & Allele 1 & Allele 2 & Allele 1 & Allele 2 \\
\hline KC035 & Case & C & G & A & A & $T$ & $\mathrm{~T}$ \\
\hline KC037 & Case & C & G & A & G & $\mathrm{T}$ & A \\
\hline KC038 & Case & C & C & A & A & T & $T$ \\
\hline KC039 & Case & G & G & G & G & A & A \\
\hline KC040 & Case & C & G & G & G & A & A \\
\hline KC041 & Case & G & G & A & G & $\mathrm{T}$ & A \\
\hline KC042 & Case & C & C & A & A & $\mathrm{T}$ & $\mathrm{T}$ \\
\hline KC043 & Case & G & G & G & G & A & A \\
\hline KC044 & Case & C & C & A & G & $\mathrm{T}$ & A \\
\hline KC045 & Case & G & G & G & G & A & A \\
\hline KC046 & Case & G & G & G & G & A & A \\
\hline KC047 & Case & C & G & G & G & A & A \\
\hline KC048 & Case & C & G & A & G & $\mathrm{T}$ & A \\
\hline KC049 & Case & C & G & A & G & $\mathrm{T}$ & A \\
\hline KC050 & Case & G & G & G & G & A & A \\
\hline KC051 & Case & G & G & G & G & A & A \\
\hline KC052 & Case & C & C & A & G & $\mathrm{T}$ & A \\
\hline KC053 & Case & G & G & G & G & A & A \\
\hline KC054 & Case & G & G & G & G & A & A \\
\hline KC055 & Case & G & G & G & G & A & A \\
\hline KC056 & Case & G & G & G & G & A & A \\
\hline KC058 & Case & G & G & G & G & A & A \\
\hline KC059 & Case & C & G & A & G & $\mathrm{T}$ & A \\
\hline KC060 & Case & C & G & G & G & A & A \\
\hline KC061 & Case & G & G & G & G & A & A \\
\hline KC062 & Case & C & G & A & G & $\mathrm{T}$ & A \\
\hline KC063 & Case & C & G & A & G & $T$ & A \\
\hline KC064 & Case & G & G & G & G & A & A \\
\hline KC065 & Case & G & G & G & G & A & A \\
\hline KC066 & Case & G & G & G & G & A & A \\
\hline KC067 & Case & G & G & G & G & A & A \\
\hline KC068 & Case & C & G & A & G & $\mathrm{T}$ & A \\
\hline KC069 & Case & G & G & G & G & A & A \\
\hline KC070 & Case & C & G & G & G & A & A \\
\hline
\end{tabular}

Table S1 (continued) 
Table S1 (continued)

\begin{tabular}{|c|c|c|c|c|c|c|c|}
\hline \multirow{2}{*}{ Sample ID } & \multirow{2}{*}{ Case/control } & \multicolumn{2}{|c|}{ rs2371597 } & \multicolumn{2}{|c|}{ rs8004137 } & \multicolumn{2}{|c|}{ rs8008602 } \\
\hline & & Allele 1 & Allele 2 & Allele 1 & Allele 2 & Allele 1 & Allele 2 \\
\hline KC071 & Case & G & G & A & G & $\mathrm{T}$ & A \\
\hline KC072 & Case & C & G & A & G & T & A \\
\hline KC073 & Case & C & G & A & G & $\mathrm{T}$ & A \\
\hline KC074 & Case & C & G & A & A & $\mathrm{T}$ & $\mathrm{T}$ \\
\hline KC075 & Case & C & G & A & G & $\mathrm{T}$ & A \\
\hline KC076 & Case & C & G & A & G & $\mathrm{T}$ & A \\
\hline KC077 & Case & G & G & G & G & A & A \\
\hline KC078 & Case & C & C & A & A & $\mathrm{T}$ & T \\
\hline KC079 & Case & G & G & G & G & A & A \\
\hline KC080 & Case & G & G & G & G & A & A \\
\hline KC081 & Case & G & G & G & G & A & A \\
\hline KC082 & Case & G & G & G & G & A & A \\
\hline KC083 & Case & C & C & G & G & A & A \\
\hline KC084 & Case & C & G & 0 & 0 & T & A \\
\hline KC085 & Case & C & G & A & G & $\mathrm{T}$ & A \\
\hline KC086 & Case & G & G & G & G & A & A \\
\hline KC087 & Case & C & C & G & G & T & T \\
\hline KC088 & Case & G & G & G & G & A & A \\
\hline KC089 & Case & C & G & A & G & $\mathrm{T}$ & $\mathrm{T}$ \\
\hline KC090 & Case & C & G & A & G & T & A \\
\hline KC091 & Case & C & C & A & A & $\mathrm{T}$ & $\mathrm{T}$ \\
\hline KC092 & Case & C & G & G & G & A & A \\
\hline KC093 & Case & C & C & A & A & $\mathrm{T}$ & A \\
\hline KC094 & Case & C & C & 0 & 0 & $\mathrm{~T}$ & A \\
\hline KC095 & Case & 0 & 0 & 0 & 0 & A & A \\
\hline KC096 & Case & 0 & 0 & 0 & 0 & A & A \\
\hline KC097 & Case & 0 & 0 & 0 & 0 & A & A \\
\hline KC098 & Case & 0 & 0 & 0 & 0 & 0 & 0 \\
\hline KC099 & Case & 0 & 0 & 0 & 0 & $T$ & A \\
\hline KC100 & Case & G & G & G & G & A & A \\
\hline KC101 & Case & 0 & 0 & 0 & 0 & 0 & 0 \\
\hline KC102 & Case & 0 & 0 & 0 & 0 & 0 & 0 \\
\hline KC103 & Case & G & G & G & G & A & A \\
\hline KC104 & Case & 0 & 0 & 0 & 0 & 0 & 0 \\
\hline
\end{tabular}

Table S1 (continued) 
Table S1 (continued)

\begin{tabular}{|c|c|c|c|c|c|c|c|}
\hline \multirow{2}{*}{ Sample ID } & \multirow{2}{*}{ Case/control } & \multicolumn{2}{|c|}{ rs2371597 } & \multicolumn{2}{|c|}{ rs8004137 } & \multicolumn{2}{|c|}{ rs8008602 } \\
\hline & & Allele 1 & Allele 2 & Allele 1 & Allele 2 & Allele 1 & Allele 2 \\
\hline KC105 & Case & C & G & A & G & $\mathrm{T}$ & A \\
\hline KC106 & Case & G & G & G & G & A & A \\
\hline KC107 & Case & C & G & A & G & $\mathrm{T}$ & A \\
\hline KC108 & Case & C & G & A & G & T & A \\
\hline KC109 & Case & C & G & A & G & $\mathrm{T}$ & A \\
\hline KC110 & Case & G & G & G & G & A & A \\
\hline $\mathrm{KC} 111$ & Case & G & G & G & G & A & A \\
\hline KC112 & Case & G & G & G & G & A & A \\
\hline KC115 & Case & C & G & A & G & $\mathrm{T}$ & A \\
\hline KC116 & Case & C & G & A & G & $\mathrm{T}$ & A \\
\hline KC117 & Case & C & G & A & G & T & A \\
\hline KC118 & Case & G & G & G & G & A & A \\
\hline KC119 & Case & C & G & A & G & T & A \\
\hline KC120 & Case & G & G & G & G & A & A \\
\hline KC121 & Case & C & G & A & G & $\mathrm{T}$ & A \\
\hline KC122 & Case & G & G & G & G & A & A \\
\hline KC123 & Case & G & G & G & G & A & A \\
\hline KC124 & Case & C & G & G & G & A & A \\
\hline KC125 & Case & G & G & G & G & A & A \\
\hline KC126 & Case & G & G & G & G & A & A \\
\hline KC127 & Case & C & G & A & G & $\mathrm{T}$ & A \\
\hline KC129 & Case & C & G & G & G & A & A \\
\hline KC130 & Case & G & G & G & G & A & A \\
\hline KC131 & Case & C & G & A & G & $\mathrm{T}$ & A \\
\hline KC132 & Case & C & C & A & A & $\mathrm{T}$ & $\mathrm{T}$ \\
\hline KC133 & Case & C & C & A & A & $\mathrm{T}$ & $\mathrm{T}$ \\
\hline KC134 & Case & C & G & A & G & $\mathrm{T}$ & A \\
\hline KC135 & Case & C & G & A & $\mathrm{G}$ & $\mathrm{T}$ & A \\
\hline KC136 & Case & G & G & G & G & A & A \\
\hline KC137 & Case & C & G & A & G & $\mathrm{T}$ & A \\
\hline KC138 & Case & C & C & A & A & $T$ & $\mathrm{~T}$ \\
\hline KC139 & Case & G & G & G & G & A & A \\
\hline KC140 & Case & G & G & G & G & A & A \\
\hline KC141 & Case & G & G & G & G & A & A \\
\hline
\end{tabular}

Table S1 (continued) 
Table S1 (continued)

\begin{tabular}{|c|c|c|c|c|c|c|c|}
\hline \multirow{2}{*}{ Sample ID } & \multirow{2}{*}{ Case/control } & \multicolumn{2}{|c|}{ rs2371597 } & \multicolumn{2}{|c|}{ rs8004137 } & \multicolumn{2}{|c|}{ rs8008602 } \\
\hline & & Allele 1 & Allele 2 & Allele 1 & Allele 2 & Allele 1 & Allele 2 \\
\hline KC142 & Case & C & G & A & G & $\mathrm{T}$ & A \\
\hline KC143 & Case & C & G & G & G & A & A \\
\hline KC144 & Case & C & G & A & G & T & A \\
\hline KC145 & Case & C & G & A & G & $\mathrm{T}$ & A \\
\hline KC146 & Case & C & G & A & G & T & A \\
\hline KC147 & Case & C & G & A & G & $\mathrm{T}$ & A \\
\hline KC148 & Case & C & G & A & G & $\mathrm{T}$ & A \\
\hline KC149 & Case & C & G & A & G & $\mathrm{T}$ & A \\
\hline KC150 & Case & G & G & G & G & A & A \\
\hline KC151 & Case & G & G & G & G & A & A \\
\hline KC152 & Case & G & G & G & G & A & A \\
\hline KC153 & Case & G & G & G & G & A & A \\
\hline KC154 & Case & C & G & A & G & $\mathrm{T}$ & A \\
\hline KC155 & Case & C & G & G & G & A & A \\
\hline KC156 & Case & G & G & G & G & A & A \\
\hline KC157 & Case & G & G & G & G & A & A \\
\hline KC158 & Case & C & G & G & G & A & A \\
\hline KC159 & Case & C & G & A & G & $\mathrm{T}$ & A \\
\hline N1 & Control & C & G & A & G & $T$ & A \\
\hline N10 & Control & G & G & 0 & 0 & 0 & 0 \\
\hline N11 & Control & 0 & 0 & A & G & $\mathrm{T}$ & A \\
\hline N2 & Control & 0 & 0 & 0 & 0 & 0 & 0 \\
\hline N3 & Control & C & G & A & G & $\mathrm{T}$ & A \\
\hline N4 & Control & 0 & 0 & A & G & $\mathrm{T}$ & A \\
\hline N5 & Control & 0 & 0 & 0 & 0 & 0 & 0 \\
\hline N6 & Control & C & G & A & G & $\mathrm{T}$ & A \\
\hline N7 & Control & C & G & A & G & $\mathrm{T}$ & A \\
\hline N8 & Control & C & G & A & G & T & A \\
\hline N9 & Control & 0 & 0 & 0 & 0 & 0 & 0 \\
\hline
\end{tabular}

